\title{
BONE HEIGHT CHANGES IN MAXILLARY ARCH OPPOSING FOUR IMPLANT RETAINED MANDIBULAR OVER DENTURES VERSUS ALL-ON-FOUR HYBRID MANDIBULAR PROSTHESES A PROSPECTIVE RANDOMIZED CLINICAL TRIAL
}

\author{
Eatemad R. Taha*, Rehab T. Elsharkawy ${ }^{* *}$, Azza Farahat Metwaly ${ }^{* * *}$ and Aly F. Fadl ${ }^{* * * *}$
}

\begin{abstract}
Statement of the problem: Endosseous implants are being increasingly used for the retention of mandibular restorations in recent years. It has been suggested that there is a risk of maxillary bone resorption under complete dentures in patients wearing mandibular implant-retained overdentures as well as mandibular all-on-four hybrid prosthesis. However, there was little evidence-based information about the effect of these 2 treatment modalities on the maxillary bone changes.

Patients and methods: This is a prospective parallel randomized controlled clinical study, in which forty eight implants were placed in mandibles of 12 completely edentulous male patients. Patients were randomly allocated into one of the two groups: group A, where 6 patients received 4 parallel implants with implant retained overdenture and group B, where 6 patients received 4 implants in the anterior part of the mandible, 2 axial implants in the center and 2 tilted implants at the distal ends with all-on four hybrid prosthesis. All patients received maxillary removable complete dentures. Radiographic evaluation was made using the CBCT to asses bone height changes that occur in the anterior and posterior maxillary areas 6 months and 12 months following denture insertion and functional loading in comparison to time of loading. Collected data were tabulated and statistically analyzed.
\end{abstract}

Results: Comparison of radiographic bone changes under complete maxillary denture at the anterior and posterior maxilla, between group A and group B, showed no significant differences between the two groups at any time interval. However, pair-wise comparison of bone height changes over time for each group showed significant difference between immediate time point and 12- month post-loading time point in group A, both in anterior and posterior maxilla, where the $\mathrm{P}$ value was $<0.05$. On the other hand there was no significant difference between the same time points in group $\mathrm{B}$, both in anterior and posterior maxilla.

*Assistant Professor, Department of Removable Prosthodontics, Faculty of Oral and Dental Medicine, Ahram Canadian University. Egypt.

**Assistant Professor, Department of Oral and Maxillofacial Surgery, Faculty of Dentistry, Cairo University. Egypt. *** Assistant Professor, Department of Removable Prosthodontics, Faculty of Dentistry, Cairo University. Egypt.

**** Lecturer, Department of Oral and Maxillofacial Radiology, Faculty of Oral and Dental Medicine, Ahram Canadian

University. Egypt. 
Conclusion: There is inevitable gradual bone loss in the maxillary arches under complete denture when opposed by four implant-retained mandibular over dentures or all-on-four hybrid mandibular prosthesis. Although the prosthesis type has no effect on the amount of bone loss, slower rate of bone resorption was found in all-on-four group throughout the study period both in anterior and posterior maxilla.

KEY WORDS: Bone changes, implant retained over denture, All-on-four hybrid prosthesis.

\section{INTRODUCTION}

Rehabilitation of edentulous mandible could be carried out through several prosthetic treatment modalities as complete dentures, removable implantretained over dentures, or fixed implant-supported prostheses. Endosseous implants are being increasingly used for the retention of restorations in recent years. Implant-retained over dentures proved to improve the retention and stability of the prosthesis when compared to complete dentures. They also improved the masticatory function, speech and patient confidence. The implant retained over denture and the fixed implant-supported prostheses also provide a higher degree of patient satisfaction and better quality of life than complete dentures. ${ }^{1-5}$

Several clinical studies have shown that two implants are sufficient to support mandibular overdentures.$^{6,7}$ However, more implants can make more rigid attachment, which would increase retention and stability of the prosthesis. Therefore, the use of four implants with ball attachment to support mandibular overdenture exhibit high denture stability and more even distribution of load. ${ }^{8}$ Elkerdawy and Radi found that ball attachment is more retentive than telescopic attachment in four implants retained mandibular overdenture. Ball attachments showed a high success rate with implant overdentures. They do not need a great prosthetic space and were claimed to be less costly, less technique sensitive and easier to clean than bars. ${ }^{10,11}$

Placement of standard implants (10-12 mm length, $\sim 3.5 \mathrm{~mm}$ diameter) in the posterior severely atrophic jaw, require an extensive surgical bone augmentation procedure to achieve sufficient bone support. The "All-on-4 "treatment concept developed by Paulo Malo and coworkers in 2003, allows the rehabilitation of edentulous jaws without bone graft in one surgical step, through the placement of 4 implants. The principle of this concept is to use four implants in the anterior part of edentulous jaws, with straight and angled multiunit abutments, aiming to provide edentulous patients with an immediately loaded fixed full arch restoration, with only four implants. The two most anterior implants are placed axially, whereas the two posterior implants are placed tilted, which enables the placement of longer implants. Resulting in improved prosthetic support with shorter cantilever arm, improved inter implant distance and improved anchorage in the bone. ${ }^{12-14}$ The distal implants could be placed with an angulation of $30^{\circ}$ as reported by many authors ${ }^{14-20}$

The All-on-4 concept has been shown to be effective with a prosthesis survival rate of $99.2 \%$ over 10 years. ${ }^{21}$ Many clinical studies have focused on the prosthesis survival rate, but their effect on the opposing arch is still controversy. Bone resorption in the anterior maxilla under complete denture has been evaluated by many investigators, when opposed by a mandibular two-implant-retained overdenture (IOD) or complete denture. Several studies found higher bone resorption in the anterior maxilla opposed by implant overdenture than the conventional complete denture. ${ }^{22-24}$ In contrast; other studies have found no difference in the residual ridge resorption rate between the two modalities of treatment or an even greater residual ridge resorption in case of conventional complete denture referred to reduced retention and stability. ${ }^{25-27}$ 
Therefore, this study was carried out as a controlled paralleled randomized clinical trial to evaluate and compare radiographic maxillary bone height changes under complete denture opposing mandibular four implants' retained overdentures or all-on-four hybrid mandibular prostheses.

\section{PATIENTS AND METHODS}

Forty eight implants were inserted in the mandibular arches of twelve completely edentulous male patients, with an age range between 51 to 64 years, who required rehabilitation of their edentulous ridges. Patients were selected from the out-patient clinic of the Prosthodontic and Oral and Maxillofacial Surgery Departments; Faculty of Dentistry, Cairo University and Ahram Canadian University. Only cases with completely edentulous maxillary and mandibular arches, with proper lower ridge that can accommodate four implants with diameters of at least $3.5 \mathrm{~mm}$ and lengths of at least $12 \mathrm{~mm}$ were included in the study. Patients also had to have healthy mucosa, sufficient interarch space, not less than $22 \mathrm{~mm}$, and Angle's class-I maxilla-mandibular relationship. Patients who were smokers, under radiotherapy or chemotherapy or bisphosphonate medications, or having any uncontrolled systemic disease that might affect the surgery or the osseointegration were excluded from the study. Patients with para-functional habits or temporomandibular joint disorders were also excluded. The study was explained in details to the patients and those who approved to participate were asked to sign an informed consent form.

Patients were randomly allocated into one of the two groups; the control group (A), where patients received four implant retained mandibular overdentures and maxillary complete denture, and the study group (B) where patients received mandibular all-on-four hybrid prosthesis and maxillary complete denture. Random allocation sequence of the participants was made with the aid of computer-generated two column tables of random numbers using www.random.org.

Conventional upper and lower complete dentures were constructed for all patients applying the balanced lingualized occlusion concept. The mandibular denture was used as a scan appliance. Patients were submitted to Cone Beam Computer Tomography scans (CBCT) for the lower arch, where a dual scan protocol was used. CBCT images were acquired using a Next Generation I-CAT scanner (Imaging Sciences International, Inc., Hatfield, USA). After that the patient's CBCT and his scan appliance data were merged using the planning software (NemoScan, Nemotec, Spain). Virtual implant planning was made using the CMI IS implants (NeoBiotech Co, Seoul, Korea). For the control group four axial parallel implants were planned for each patient, while in the study group, we planned for two axial implants in the center and two tilted implants at the distal ends. The distal implants placed at $30^{\circ}$ angle to the crest of the ridge to accept SCRP multi-unit abutment (NeoBiotech Co, Seoul, Korea). Finally a mucosa supported surgical guide was printed and prepared to be used during surgery for each case.

Surgical phase: Before the surgery patients were given 4 capsules of $500 \mathrm{mg}$ amoxicillin (Amoxil, Medical Union Pharmaceuticals (MUP), Egypt) and they were asked to use chlorohexidine mouth rinse (Hexitol, The Arab Drug Company ADCO, Egypt). Soft tissue discs were removed from the crest of the ridge in the proposed implants' positions using tissue punch, the surgical guide was fixed in position and implants osteotomy sites were prepared using drills of the 3DDX universal kit (3 DDX, Boston, USA). After the last drill, the sites were irrigated with saline and the four implants (NeoBiotech Co., Seoul, Korea) were driven down and tightened in to their prepared sites, finally the implants were covered with healing caps. After surgery, the denture was then relived and lined with tissue conditioning material to assure a comfortable and accurate fit. 
Patients were instructed to eat only soft diet for one week without denture removal, rinse their mouth with Chlorohexidine mouth wash twice daily for 2 weeks, and they were asked to take amoxicillin 500 mg Capsules and Ibuprufen $400 \mathrm{mg}$ tablets (Brufen, Kahira Pharm. \& Chem. Ind. Co., Egypt) every 8 hours for 5 days. Panoramic radiograph was taken at the end of this visit with the denture in place to ensure proper implant placement.

Prosthetic phase: One week after surgery, the dentures were removed and prosthetic steps were started to construct the permanent prosthesis. For Group (A): healing caps were removed and Ball attachments were inserted onto implants with the caps on. Flexible sleeves were slipped over the abutment to prevent self-cured resin from running into the sulcus and to block the undercuts. The previously constructed mandibular denture was relived in areas opposite to implants to accommodate for ball attachments. Cold-cure resin (Rebaron. GC Corporation. Tokyo. Japan) was injected into the relieved areas of the mandibular denture and patients were instructed to wear the upper denture. The mandibular denture was inserted into the patient's mouth and patients were instructed to close in maximum inter-cuspal position until complete polymerization of the material occurred. Denture was then removed with the caps picked-up in its fitting surface, the plastic sleeves were removed and the denture was trimmed and polished and delivered to the patients (fig. 1).

For group B: Healing caps were removed and multi-unit abutments were screwed into the implants. Impression was taken for the lower ridge and study model was made to construct a customtray with windows cut over the implants. The transfer copings were screwed to the abutments using long fixation screws. Acrylic resin rods was premade on the study casts to splint the impression copings together. They were fixed in place in the patient's mouth using duralay self-cure acrylic resin (Reliance, IL, USA). Impression was registered in polyether material using an open tray splinted technique (fig 2). Master cast was fabricated and

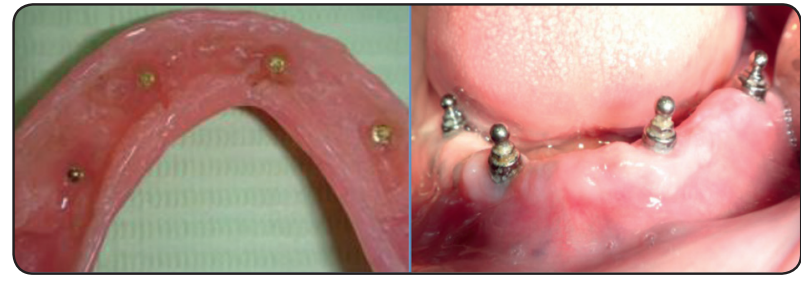

Fig. (1) Group A: Mandibular implant overdenture retained with four ball attachments.

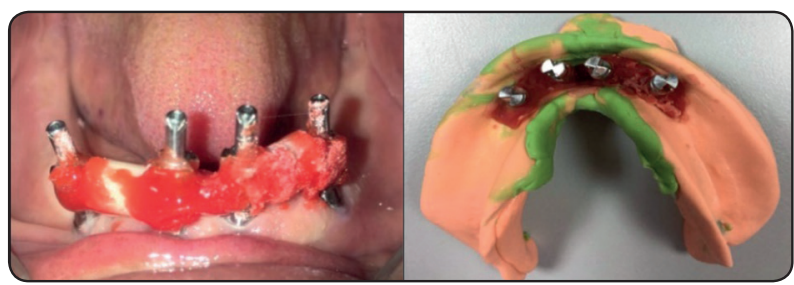

Fig. (2) Group B, all-on-four hybrid prosthesis: Open tray splinted impression technique.

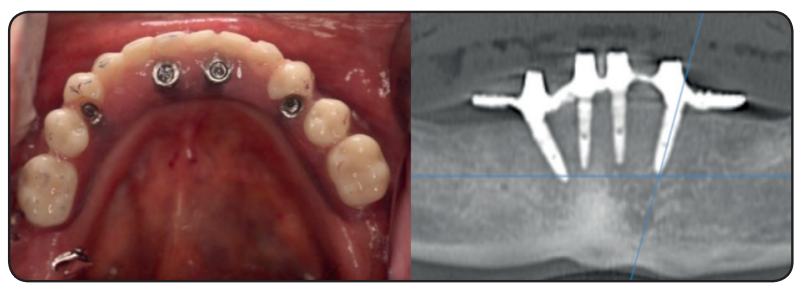

Fig. (3) Group B, all-on-four- hybrid prosthesis: photograph and Radiograph.

the implant analogues were fixed in their specific position inside the cast. A finished metal framework was tried in the patient's mouth to assure passive fit. A wax rim was built over the metal framework and the vertical dimension and bite registration were taken. Teeth arrangement and try- in was carried out then final prosthesis was made and screwed into the abutments (fig 3).

\section{Radiographic Evaluation}

Radiographic evaluation was made using the cone beam computed tomography (CBCT) (I-CAT, Imaging Sciences International, Hatfield, USA) to asses bone height of the anterior and posterior maxillary areas at loading, 6 months, and 12 months following denture insertion and functional loading. Assessment was carried-out with the aid of specific radiographic stents in the areas of interest. 


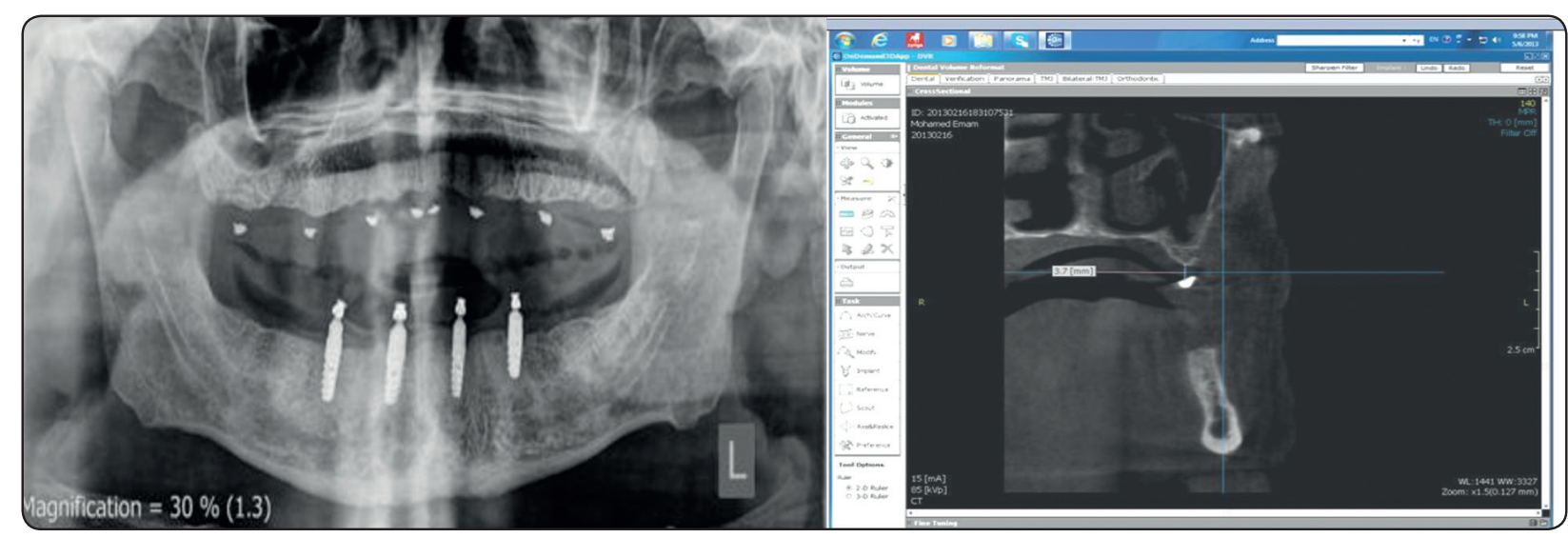

Fig (4) Radiographic bone height measurements in the maxilla. N.B. the CBCT was taken for the maxillary area only so the radiographic assessor was blinded regarding the groups as well as the statistician.

Duplicates of maxillary complete dentures in clear acrylic resin were used as radiographic stents. Size 2 round carbide burs were used to create 8 depressions or cavities ( 4 on each side bilaterally) in the fitting surface of the radiographic stents at the areas of upper central incisors, canines, first molars and maxillary tuberosities. These depressions were filled with warm condensed Gutta-percha pressed to be used as radiopaque markers and reference points for measuring the crestal bone height changes in the maxillary anterior and posterior regions (fig. $4)$. The vertical (linear) distance from the top of the radiopaque markers to the crest of the residual ridge in those corresponding areas was measured digitally on the CBCT. The increase in the length of the measurements of the vertical (linear) distance in any area means increase in the bone loss (changes) in that area. A mean value of both right and left sides of each tomogram was calculated.

Statistical analysis: Data were coded and entered using the statistical package SPSS (Statistical Package for the Social Sciences) version 25. Data was summarized using mean and standard deviation in quantitative data. Comparisons between groups were done using unpaired t test. For comparison of serial measurements within each group repeated measures ANOVA was used. P-values less than 0.05 were considered as statistically significant

\section{RESULTS}

Postoperative healing was uneventful in all patients. All patients completed the follow up period with no attrition of the sample. All implants in both groups were considered successful as they were all, immobile when manually examined, there were no pain or suppuration around the implants and there were no evidence of peri-implant radiolucency in the x-rays.

Comparison of Radiographic bone changes under the complete denture at the anterior maxilla, between group A and group B, showed no significant difference between the 2 groups at any time point, Immediate, 6 months, and 12 months after loading, values are presented in Table 1 and fig.5. In the posterior maxilla, as in the anterior maxilla, there was no significant difference between the 2 groups at any time point; values are presented in Table 2 and fig. 6.

The results of the pair-wise comparison of bone height changes between each two time points within each group, both for anterior and posterior maxilla are shown in table 3. Regarding the mean differences of bone level over time in group A, there were statistical significant differences between time points throughout the study period, in both anterior and posterior maxilla, where the $\mathrm{P}$ value was $<0.05$, except for the time interval from denture insertion 
TABLE (1) The values of anterior maxilla bone changes in the two groups along the study period.

\begin{tabular}{|c|c|c|c|c|c|c|c|}
\hline \multirow{2}{*}{\multicolumn{2}{|c|}{ Anterior maxilla }} & \multicolumn{2}{|c|}{ Immediate } & \multicolumn{2}{|c|}{6 months } & \multicolumn{2}{|c|}{12 months } \\
\hline & & Mean & SD & Mean & SD & Mean & SD \\
\hline \multirow{4}{*}{$\begin{array}{c}\text { Bone height } \\
(\mathrm{mm})\end{array}$} & Group A & 3.69 & 0.32 & 3.77 & 0.30 & 3.80 & 0.30 \\
\hline & Group B & 3.84 & 0.30 & 3.88 & 0.30 & 3.89 & 0.30 \\
\hline & t value & \multicolumn{2}{|c|}{0.817} & \multicolumn{2}{|c|}{0.625} & \multicolumn{2}{|c|}{0.507} \\
\hline & P value & \multicolumn{2}{|c|}{0.433} & \multicolumn{2}{|c|}{0.546} & \multicolumn{2}{|c|}{0.623} \\
\hline
\end{tabular}

*Statistically significant at $p \leq 0.05$

TABLE (2) The values of posterior maxilla bone changes in the two groups along the study period:

\begin{tabular}{|c|c|c|c|c|c|c|c|}
\hline \multicolumn{2}{|c|}{ posterior maxilla } & \multicolumn{2}{|l|}{ Immediate } & \multicolumn{2}{|l|}{6 months } & \multicolumn{2}{|l|}{12 months } \\
\hline & & Mean & SD & Mean & SD & Mean & SD \\
\hline \multirow{4}{*}{$\begin{array}{l}\text { Bone height } \\
(\mathrm{mm})\end{array}$} & Group A & 3.59 & 0.36 & 3.61 & 0.37 & 3.63 & 0.36 \\
\hline & Group B & 3.81 & 0.29 & 3.87 & 0.28 & 3.88 & 0.28 \\
\hline & t value & \multicolumn{2}{|c|}{1.201} & \multicolumn{2}{|c|}{1.391} & \multicolumn{2}{|c|}{1.329} \\
\hline & P value & \multicolumn{2}{|c|}{0.257} & \multicolumn{2}{|c|}{0.194} & \multicolumn{2}{|c|}{0.213} \\
\hline
\end{tabular}

*Statistically significant at $p \leq 0.05$

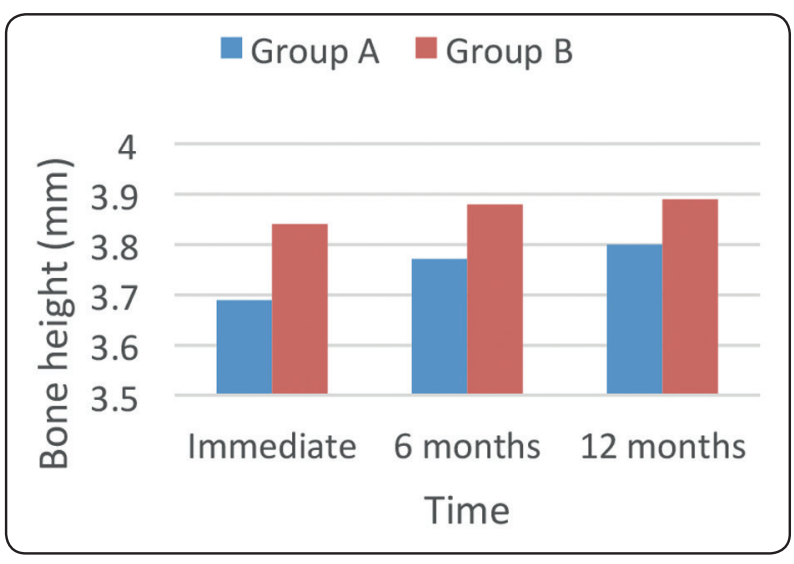

Fig. (5) Bar chart showing the Bone height changes comparison between the 2 groups at the anterior maxilla at each time point of the study.

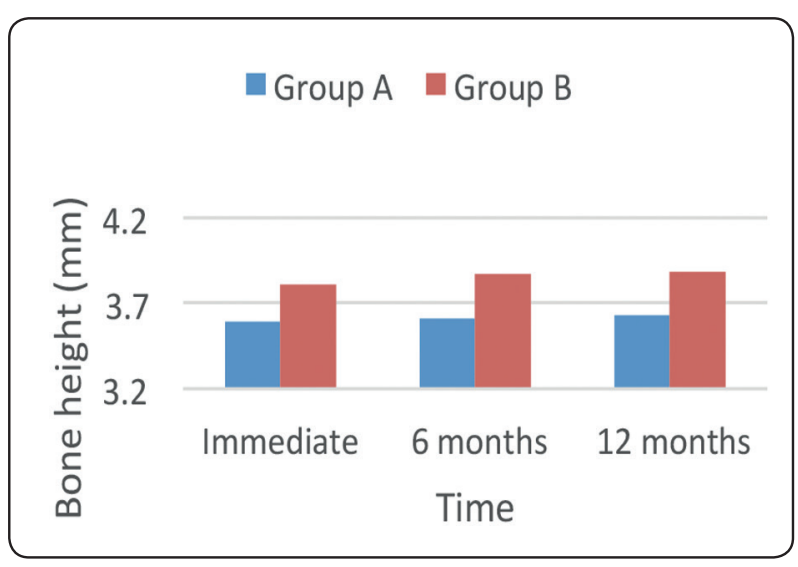

Fig. (6) Bar chart showing the Bone height changes comparison between the 2 groups at the posterior maxilla at each time point of the study. 
TABLE (3) The effect of time on bone height changes in the anterior and posterior maxilla for the two studied groups

\begin{tabular}{|c|c|c|c|c|c|}
\hline & & & Mean difference & SD & P value \\
\hline \multirow{6}{*}{ 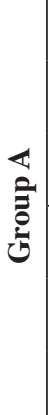 } & \multirow{3}{*}{ Bone height of anterior maxilla (MM) } & Immediate - 6 months & .03833 & .01835 & $0.011^{*}$ \\
\hline & & Immediate - 12months & .11000 & .02000 & $<0.001 *$ \\
\hline & & 6 Months - 12months & .07167 & .03061 & $0.007 *$ \\
\hline & \multirow{3}{*}{ Bone height of posterior maxilla (MM) } & Immediate - 6 months & .02667 & .03670 & 0.060 \\
\hline & & Immediate - 12months & .04667 & .03615 & $<0.001^{*}$ \\
\hline & & 6 Months - 12months & .02000 & .00632 & $<0.001^{*}$ \\
\hline \multirow{6}{*}{ 象 } & \multirow{3}{*}{ Bone height of anterior maxilla (MM) } & Immediate - 6 months & .01667 & .01211 & 0.406 \\
\hline & & Immediate - 12months & .05333 & .01033 & 0.075 \\
\hline & & 6 Months - 12months & .03667 & .00816 & $0.002 *$ \\
\hline & \multirow[t]{3}{*}{ Bone height of posterior maxilla (MM) } & Immediate - 6 months & .01333 & .01506 & .082 \\
\hline & & Immediate - 12months & .07333 & .07367 & .059 \\
\hline & & 6 Months - 12months & .06000 & .07849 & .120 \\
\hline
\end{tabular}

*Statistically significant at $p \leq 0.05$

to six months in the posterior maxilla. On the other hand in group B, the all-on-four hybrid prosthesis, the pair-wise comparison of bone height changes over time showed that there were no significant difference throughout the study period in both anterior and posterior maxilla (where the $\mathrm{P}$ value $>0.05$ ), except for the time interval from six to twelve months in the anterior maxilla.

\section{DISCUSSION}

All patients of this study were satisfied with their implant prostheses in both groups. All implants were osseointegrated. Patients were pleased with the excellent retention, stability, the higher biting force $\&$ the improved masticatory efficiency of their four implant mandibular overdentures or all on four implant hybrid prostheses. Patients were rehabilitated with maxillary complete dentures; optimal maxillary denture fit and better stress distribution of the denture was achieved by giving special attention with regard to the prosthetic after care. ${ }^{28}$ This study was conducted to compare the effect of two designs of mandibular implant prostheses on the bone height changes in the opposing maxillary arch.

The results of the present study revealed that an ongoing bone resorption of the anterior maxilla had occurred during study period which was significant for the two studied groups at the period from 6- 12 months interval. These results agree with the findings of previous studies that reported gradual maxillary bone resorption in patients wearing complete dentures opposing implantretained overdentures. ${ }^{29,30}$ Those authors attributed these findings to the instability of the complete dentures, which contributed to an un-favorable stress distribution among the denture-bearing areas. On the contrary, authors such as Närhi et al. $2000^{27}$ 
and Jacobs et al. $1993^{31}$ did not find statistically significant differences in premaxillary bone loss for conventional denture or implant overdentures.

Bone resorption was more pronounced in the anterior maxillary region than posterior area; this finding was in accordance with Kreisler et al. 2003, ${ }^{32}$ who observed greater resorption in the anterior part of the maxilla than in the posterior part, with a premaxilla loss percentage of between $5 \%$ and $12 \%$. This may be attributed to the increase in the biting forces exerted by the mandibular prostheses. However; the amount of bone resorption reported in this study much less than those recorded in two implant retained overdentures. ${ }^{32}$

Several factors could contribute to these findings. First, all patients in the present study were rehabilitated with a lingualized occlusion concept to avoid too much anterior pressure. This concept with no anterior teeth contact has also been recommended for implant-retained mandibular overdentures to preserve anterior maxillary bone. The maxillary complete dentures were evaluated periodically to ensure optimal maxillary denture fit and better stress distribution. Furthermore, better load distribution and denture stability were reported in implant overdentures retained with four implants and in fixed hybrid prosthesis. ${ }^{8}$

The differences between the two groups were statically insignificant in this study which supported by the finding of Eliasson et al. who observed a total of 119 patients had been treated with a fixed restoration on 4 implants. They reported its effect on the opposing jaw and found that there was no significant difference in bone loss with regard to the opposing jaw restoration ${ }^{33}$

\section{CONCLUSIONS:}

There is inevitable gradual bone loss in the maxillary arches under complete denture when opposed by four implant-retained mandibular over dentures or all-on-four hybrid mandibular prosthesis. Although the prosthesis type has no effect on the amount of bone loss, slower rate of bone resorption was found in all-on-four group throughout the study period both in anterior and posterior maxilla.

\section{REFERENCES}

1. Att W, Bernhart J, Strub JR. Fixed rehabilitation of the edentulous maxilla: possibilities and clinical outcome. J Oral Maxillofac. Surg. 2009; 67:60-73.

2. Att W, Stappert C. Implant therapy to improve quality of life. Quintessence Int. 2003; 34:573-581.

3. Doundoulakis J H, Eckert S, Lindquist C C, Jeffcoat M K. The implant supported overdenture as an alternative to the mandibular complete denture. J Am Dent Assoc 2003; 134: $1455-1458$

4- Assuncao WG, Zardo GG, Delben JA, Barão VA: Comparing efficacy of mandibular implant-retained overdentures and conventional dentures among elderly edentulous patients: satisfaction and quality of life. Gerontology 2007; 24: 235-238

5- Oh SH, Kim Y, Park JY, Jung YJ, Kim SK and Park SY: Comparison of fixed implant supported prosthesis, removable implant supported prosthesis, and complete dentures: patient satisfaction and oral health-related quality of life. Clin Oral Implants Res. 2016, 2 (7)

6- Burns DR, Unger JW, Coffey JP, Waldrop TC, Elswick RK Jr. Randomized, prospective, clinical evaluation of prosthodontic modalities for mandibular implant overdenture treatment. J Prosthet Dent 2011; 106: 12-22

7- Raghoebar GM, Meijer HJ, Slot W, Slater JJ, Vissink A. A systematic review of implant-supported overdentures in the edentulous maxilla, compared to the mandible: How many implants? Eur J Oral Implantol 2014; 7 (2):191-201

8. Bilhan H, Geckili O, Mumcu E, Cilingir A, Bozdag E. The influence of implant number and attachment type on maximum bite force of mandibular overdentures: a retrospective study. Gerodontology. 2012 ;29 (2):116-20.

9- ElKerdawy MW, Radi IA. Effect of dislodging forces on mandibular implant attachmentretained overdenture. Implant Dent. 2011; 20(3):246-54.

10- John J, Rangarajan V, Savadi RC, Satheesh Kumar KS, Satheesh Kumar P. A finite element analysis of stress distribution in the bone, around the implant supporting a mandibular overdenture with ball/o ring and magnetic attachment. J Indian Prosthodont Soc. 2012; 12: 37-44

11- Sadig W. A comparitive in vitro study on the retention and stability of implant-supported over dentures. Quintessence Int. 2009; 40(4): 313-319. 
12- Maló P, De Araujo D, Nobre, MA., Lopes AV, Ferro A and Gravito I, "All-on-4 treatment concept for the rehabilitation of the completely edentulous mandible: a 7 year clinical and 5 year radiographic retrospective case series with risk assessment for implant failure and marginal bone level. Clinical Implant Dentistry and Related Research. 2015; 17: 531-541

13- Malo P, Rangert B, Nobre M. "All-on-Four" immediate function concept with Branemark System implants for completely edentulous mandibles: a retrospective clinical study. Clin Implant Dent Relat Res 2003; 5 (1): 2-9.

14- Christopher CK Ho. Implant rehabilitation in the edentulous jaw: The "All-on-4® concept" immediate function. Australian dental practice. 2012:138-48.

15- Begg T1, Geerts GA, Gryzagoridis J. Stress patterns around distal angled implants in the All-on-4® concept configuration. Int J Oral Maxillofacial implants. 2009; 24: 663-71.

16- Tallarico M, Meloni SM, Canullo L, Caneva M, Polizzi G. FiveYear Results of a Randomized Controlled Trial Comparing Patients Rehabilitated with Immediately Loaded Maxillary Cross-Arch Fixed Dental Prosthesis Supported by Four or Six Implants Placed Using Guided Surgery. Clin Implant Dent Relat Res. 2016;18:965-72.

17. Francetti L, Agliardi E, Testori T, Romeo D, Taschieri S, Fabbro MD. Immediate rehabilitation of the mandible with fixed full prosthesis supported by axial and Tilted implants: Interim results of a single cohort prospective study. Clin Implant Dent Relat Res. 2008;10: 255-63. 18.

18. Crespi R, Vinci R, Cappare P, Romanos GE, Gherlone E. A clinical study of edentulous patients rehabilitated according to the "all on four" immediate function protocol. Int J Oral Maxillofac Implants. 2012; 27: 428-34.

19- Butura CC, Galindo DF, Jensen OT. Mandibular AllOn-Four Therapy Using Angled Implants:A ThreeYear Clinical Study of 857 Implants in 219 Jaws. Oral Maxillofac Surg Clin North Am.2011; 23: 289300. 33.

20-Cavalli N, Barbaro B, Spasari D, Azzola F, Ciatti A, Francetti L. Tilted implants for full-arch rehabilitations in completely edentulous maxilla: a retrospective study. Int J Dent. 2012; 2012: 180379.

21 -Malo P, de Araujo Nobre M, Lopes A, Moss SM, Molina GJ. A longitudinal study of the survival of All-on-4 implants in the mandible with up to 10 years of follow-up. J Am Dent Assoc 2011; 142: 310-320
22-. Lopez-Roldan A, Abad DS, Bertomeu IG Castillo EG, Otaolaurruch ES. Bone resorption processes in patients wearing overdentures. a 6-year retrospective study. Med Oral Patol Oral Cir Bucal 2009; 14: 203-209

23. Abd-ELDayem M, Assad A, Abd-ElGhany M: The effect of different mandibular dentures on antagonistic maxillary ridge. Implant Dent 2007; 16: 421-430

24- El sayed MA, Ashmawy TM,Faramawy AG: The influence of resilient liner and clip attachments for bar -implantretained mandibular overdentures. A 5-year randomized clinical trial. J. Oral Rehabil, 2014, 41: 69-77

25- Rutkunas V, Mizutani H, Maxillary complete denture outcome with two implant supported mandibular overdentures. A systematic review. Stomatologija 2008; 10: 10

26- Tymstra N, Raghoebar GM, Vissink A, Meijer HJ. Maxillary anterior and mandibular posterior residual ridge resorption in patients wearing a mandibular implantretained overdenture. J Oral Rehab, 2011, 38(7):509-16

27- Narhi T, Geertman M, Hevinga M: Changes in edentulous maxilla in persons wearing implant-retained mandibular overdentures, J Prosthetic Dent.2000; 84:43-52

28- Meijer HJ, Raghoebar GM, Van't Hof MA. : Comparison of implant-retained mandibular overdentures and conventional complete dentures: a 10-year prospective study of clinical aspects and patient satisfaction. Int J Oral Maxillofac Implants2003; 18:879-885.

29- Schwartz-Arad D, Kidron N, Dolev E.: A long-term study of implants supporting overdentures as a model for implant success J Periodontol 2005; 76: 1431-5.

30-Lechner SK, Mammen A.: Combination syndrome in relation to osseointegrated implant-supported overdentures: a survey, Int J Prosthodont 1996; 9: 58-64.

31- Jacobs R, van Steenberghe D, Nys M, Naert I. Maxillary bone resorption in patients with mandibular implantsupported overdentures or fixed prostheses. J Prosthet Dent. 1993; 70: 135-40.

32- Kreisler M, Behneke N, Behneke A, d’Hoedt B. Residual ridge resorption in the edentulous maxilla in patients with implant-supported mandibular overdentures: an 8- year retrospective study. Int J Prosthodont. 2003; 16: 265-300.

33- Eliasson A, Palmquist S, Svenson B, Sondell K. Five-year result with fixed complete-arch mandibular prostheses supported by 4 implants. Int J Oral Maxillofac Implants. 2000; 15: 505-510. 